\title{
227 REPRODUCTIVE ANATOMY OF THE FEMALE GREY SHORT-TAILED OPOSSUM (MONODELPHIS DOMESTICA): CONSIDERATIONS FOR DEVELOPING ARTIFICIAL INSEMINATION BY CATHETER
}

\author{
D. B. B. P. Paris \\ Institute of Biomedical \& Life Sciences, University of Glasgow, Glasgow, Scotland, UK
}

\begin{abstract}
Due to the variability in vaginal anatomy among marsupials, the female reproductive tract must be examined for each species prior to developing artificial insemination using catheters. The grey short-tailed opossum (Monodelphis domestica) is a nonseasonal, polyovular didelphid and, as in all marsupials studied, has two completely separate uteri each opening into an anterior vaginal expansion through two distinct cervices. In the opossum, however, a septum divides the anterior vaginal expansion into two vaginal culs-de-sac, two lateral vaginae connect the anterior vaginal culs-de-sac to the urogenital sinus and opening, and the median vagina is a transient pseudo-vaginal birth canal. In this study we examined the site for insertion of artificial insemination catheters and the distribution of fluids inseminated within the vaginal complex of the opossum. Reproductive tracts were examined from four similarly sized unpaired adult one- to two-year-old females. A $2.3 \mathrm{~mm}$ diameter silicon balloon HSG catheter or a $0.8 \mathrm{~mm}$ diameter malleable obturator (Cook Australia, Brisbane, Australia) was introduced at the urogenital opening and navigated through the urogenital sinus, lateral vaginae, and cervices and the depth of insertion noted. Second, $0.15 \mathrm{~mL}$ of $1 \%$ Methylene blue dye (Sigma, Poole, UK) was injected by HSG catheter into the anterior urogenital sinus and the extent of dye distribution in the tract noted. In all tracts, the HSG catheter easily reached the anterior urogenital sinus $(1.5 \pm 0.3 \mathrm{~cm}$; mean $\pm \mathrm{SEM})$, but would not pass into the lateral vaginae or bladder. The malleable obturator easily passed into the bladder or through each lateral vagina into the anterior vaginal cul-de-sac $(2.9 \pm 0.2 \mathrm{~cm})$. The obturator also passed through the each cervix into the opening of the uterus $(3.1 \pm 0.3 \mathrm{~cm})$, but the tract required manipulation to navigate it through the convoluted lateral vaginae. Dye injected into the anterior urogenital sinus was distributed throughout the lateral vaginae and anterior vaginal culs-de-sac. No dye was detected in the bladder or had passed through the cervices into the uteri. In two of three tracts studied, dye was observed to migrate between each anterior vaginal cul-de-sac across the posterior end of the median septum that divides them. In conclusion, the use of larger diameter catheters $(\sim 2.3 \mathrm{~mm})$ is recommended for unguided insemination of the anterior urogenital sinus in this species. Catheters less than $1 \mathrm{~mm}$ diameter require ultrasonic or endoscopic guidance to reach the uteri in order to avoid insemination into the bladder. Dye studies indicate that the median septum may not completely separate the cervices in the opossum, suggesting that inseminates delivered to one side of the tract may be able to fertilize oocytes on the contralateral side. In addition, the cervices appear to restrict inseminates from entering the uteri. Spermatozoa may thus be required to pass through the cervices under their own motility.
\end{abstract}

This work was funded by the European Commission under a Marie Curie Incoming International Fellowship. Catheters were provided by Cook Australia. 